Revista de la red interuniversitaria de estudios sobre las literaturas rioplatenses contemporáneas en Francia

$11 \mid 2014$

De niños e infancias

\title{
Las armas y las lenguas. Borges y la Gran Guerra
}

\section{Gersende Camenen}

\section{OpenEdition}

\section{Journals}

Edición electrónica

URL: http://journals.openedition.org/lirico/1788

DOI: $10.4000 /$ lirico. 1788

ISSN: 2262-8339

Editor

Réseau interuniversitaire d'étude des littératures contemporaines du Río de la Plata

\section{Referencia electrónica}

Gersende Camenen, «Las armas y las lenguas. Borges y la Gran Guerra », Cuadernos LIRICO [En línea], 11 | 2014, Puesto en línea el 01 diciembre 2014, consultado el 01 mayo 2019. URL : http:// journals.openedition.org/lirico/1788; DOI : 10.4000/lirico.1788

Este documento fue generado automáticamente el 1 mayo 2019.

\section{(c) (i) (9)}

Cuadernos LIRICO está distribuido bajo una Licencia Creative Commons Atribución-NoComercialSinDerivar 4.0 Internacional. 


\title{
Las armas y las lenguas. Borges y la Gran Guerra
}

\author{
Gersende Camenen
}

1 Los años de la Primera Guerra Mundial son los de la tardía infancia de Borges. De su experiencia, ginebrina, de la guerra da cuenta el relato de su Autobiografía mientras que algunos poemas y textos críticos de los años 1919-1921'1 así como su correspondencia con los amigos europeos de esa época de iniciación ${ }^{2}$, transmiten todavía el eco de la catástrofe mundial. La coincidencia histórica entre la guerra, el acontecimiento que abre el siglo XX, y el período de formación del escritor llama la atención. Si "l'événement est ce qu'il devient" (de Certeau), el acontecimiento, como objeto disruptivo, constituye un inicio, pero un inicio en el cual las huellas son lo que importa (Dosse, 2010: 1). La misma definición se puede aplicar a la infancia: la infancia es su devenir. ¿Cómo Borges construye estos dos inicios que son la guerra y la infancia? ¿Cuál es la impronta dejada por este acontecimiento histórico de amplitud inaudita en un adolescente en formación cuyas experiencias y emociones son todavía las de una prolongada infancia? ¿Nos enseña algo la coincidencia de estos dos inicios, histórico y literario, colectivo e individual ?

2 La lectura que se propone aquí es el fruto de un determinada coyuntura histórica que no deja de producir sus efectos. La celebración del centenario de la guerra del 14 es hoy en Francia la ocasión de un vasto ejercicio de memoria colectiva, practicado desde muchos ámbitos, tanto institucionales como académicos y editoriales. Más allá de la conmemoración patrimonial (y quizás en contra de ella) volver, desde una mirada argentina, sobre la Primera Guerra Mundial es una manera de pensar el principio de la decadencia europea ${ }^{3}$ y la incipiente reorganización política del mundo que no dejó inmune al propio sistema literario hasta entonces dominado por Francia ${ }^{4}$. En la guerra se jugó también el porvenir mundial de las letras y de las lenguas. Borges fue un testigo y un actor de este profundo cambio. ¿De qué manera? Es lo que nos proponemos examinar. 


\section{La biblioteca y la trinchera}

3 Un primer acercamiento a la Autobiografía parecería indicar que la incidencia de la Gran Guerra en Borges es escasa. El relato de los años 1914-1919 en Europa difundido y analizado por los biógrafos del autor es conocido. A principios de 1914, la familia Borges viaja a Suiza por razones médicas (encontrar una cura a la incipiente ceguera del padre) y educativas (perfeccionar la educación cosmopolita de Georgie y Norah en un colegio francófono). Aprovechando la comodidad de un cambio monetario ventajoso, la familia se pasea por Londres y París y disfruta de los museos antes de quedar atrapada, después del asesinato del emperador Franz Joseph y la consiguiente declaración de guerra, en una Alemania hostil. Suiza, neutral, se presenta más que nunca como un inesperado refugio para los atribulados turistas. Los cuatro años de guerra y "estadía forzada" (Monegal, 1985 : 97) para la familia serán sin embargo años de formación y meditación en el retiro suizo : colegio, amistades y lecturas operan el paso de la infancia a la adolescencia, una época de contornos todavía borrosos tanto social como psicológicamente.

La ironía de la situación no escapa a Borges quien, en una entrevista con César Fernández Moreno en 1967, atribuye la repentina decisión de viajar al viejo continente en vísperas de la contienda mundial a la total ignorancia por parte de su familia de la "historia universal" (Monegal, 1987: 98): "Pero éramos tan ignorantes de la historia, que no teníamos la menor idea de que en agosto estallaría la primera Guerra Mundial" (Borges, 1999, 27). La anécdota, que para una mirada europea roza lo escandaloso, contiene sin embargo elementos claves de la mitología personal del escritor. En efecto, el binomio biblioteca suiza versus campo de batalla europeo retoma la famosa oposición cultural y familiar de las armas y las letras, este fundamento del mito "de desesperación" y "de compensación" del escritor, heredero infeliz de una familia de ilustres guerreros que encuentra en los libros lo que le faltaba en la vida "real" (Monegal, 1987: 19). Pero la guerra, lejos de ofrecer una ocasión para honrar la ilustre memoria familiar (aunque sea manifestando un simple interés de testigo cercano a los hechos), confirma al contrario el destino letrado del joven Borges.

Por otra parte, la clásica oposición entre las letras y las armas, forjada en la memoria familiar y argentina, adquiere aristas nuevas una vez trasladada a Europa: la incomprensión, teñida de indiferencia frívola, de la familia ante la guerra europea sirve para afirmar el destino literario de Borges. Flâneurs ociosos en un continente en llamas, los Borges ilustran la posición ambivalente de la clase alta argentina frente a Europa. Con la guerra, irrumpe con violencia el tiempo histórico. La Europa-museo, biblioteca o emporio de los argentinos que viajan era, como lo demostró Viñas, el lugar del pasado de una cultura clásica y moderna o del presente fijo de un mercado de bienes disponibles. Manifestando una temporalidad en la cual los argentinos no caben, la guerra pone de realce, en clave irónica y ligera, un sentimiento de no-pertenencia. La guerra es un asunto de europeos. En la lógica simbólica de la autobiografía (y de la mitología del escritor), la extranjería de la familia Borges se transforma en extrañeza en la mirada del adolescente, para quien la guerra habría sido un período de reclusión forzada pero fértil, cuando no un largo bostezo. La extrañeza de Borges frente a la guerra prepara de esa manera el regreso literario a América y la guerra ilustra la búsqueda de un lugar de enunciación frente a Europa, fruto de una compleja negociación entre el cosmopolitismo y el nacionalismo ${ }^{5}$. 
6 La concentración en la Autobiografía de los mitemas borgeanos, reunidos en la evocación de la guerra, se explica por el contexto de publicación de la autobiografía. Publicada en inglés en 1970 en la prestigiosa revista The New Yorker y poco después como introducción a la edición norteamericana de The Aleph and Other Stories, la autobiografía es parte del proceso de conquista borgeana de la crítica y de la academia anglosajonas y pertenece al vasto archivo textual e iconográfico que Borges manipula con pericia a partir de los años 70, asumiendo la escisión entre el texto y la figura pública del escritor, esta paradoja según la cual no hay autonomía literaria sin culto del escritor (Viala, 1985).

7 Más allá de la mitología del escritor, la intrascendencia de la guerra ilustra también los fundamentos del sistema "metafísico" y literario de Borges : la dimensión inmanente del acontecimiento, la refutación de la causalidad y del tiempo históricos ("Nueva refutación del tiempo", Otras inquisiciones, 1952) y de la unidad psicológica de un "yo de conjunto" ("La Nadería de la personalidad", Inquisiciones, 1925) enunciados desde los años 20. Retomados en el contexto de la canonización del escritor, estos postulados decisivos favorecieron la recepción de un Borges abstracto, autor de laberintos metafísicos poblados de enigmáticos tigres, y totalmente ajeno al curso de la Historia. Una figura descontextualizada que la recepción internacional, y el propio Borges, contribuyeron a construir ${ }^{6}$.

8 Ahora bien, la evocación de la guerra, a pesar de la aparente indiferencia de Borges frente al drama de una Europa ardiendo a sus puertas, y más allá de su rol en la confirmación de los tópicos borgeanos, deja entrever todo un juego de tensiones geopolíticas y lingüísticas fundadoras para el entonces joven Borges. Nuestra idea es que incluso en su juego con la recepción que lo lleva a asumir una actitud indiferente ante la historia, la autobiografía de Borges traduce una experiencia de la guerra, trasladada hacia un imaginario lingüístico forjado por la guerra de culturas y lenguas que fue también la Primera Guerra Mundial. En efecto, si bien por razones tanto generacionales y circunstanciales (Borges es un adolescente de catorce años "encerrado" en Suiza) como ideológicas (no comparte, como lo veremos a continuación, el análisis nacionalista de la guerra), Borges, que al contrario de Lugones ${ }^{7}$ no pudo (ni quiso retrospectivamente) asumir la postura del testigo y del analista, no fue sin embargo ajeno a la guerra y la vivió desde otro ángulo ${ }^{8}$. La guerra de Borges fue un acontecimiento lingüístico e imaginario, el privilegio, quizás, de la experiencia infantil y juvenil de la Historia. Las pruebas de esta singular vivencia son por un lado el relato de aprendizaje de las lenguas en la Autobiografía y por otro los textos traducidos del alemán o al francés o escritos en francés por Borges durante la guerra.

\section{Lenguas en pugna}

9 Uno de los motivos que se destacan del relato de estos años es el aprendizaje y la práctica de nuevas lenguas : Borges aprende el francés, estudia el latín y descubre el alemán. En el patio de recreos está en contacto, por sus amigos judíos, con el yiddish y el polaco. El italiano de la plurilingüe suiza y de las escapadas a Verona nunca está lejos. En otras palabras, el "encierro" provocado por la guerra enriquece el complejo imaginario lingüístico del escritor, ya desgarrado por un doble código privado (el inglés y el español) (Monegal, 1987 : 24-29). Si se escribe a partir de un imaginario de la lengua y del estilo (Philippe, 2013), no cabe duda de que estos años de intenso contacto con varias lenguas son decisivos para el escritor. 
10 Pero sobre todo, lo que nos enseña el relato de aprendizaje en Suiza es que la coexistencia de estas lenguas no es pacífica. El multilingüismo no es una experiencia serena y conciliadora: las lenguas son fuerzas en pugna que provocan adhesión o rechazo. Las resistencias, los rencores y las preferencias del joven políglota transmiten el eco no tan lejano de la contienda militar. En el recuento del aprendizaje que propone Borges, cada lengua se tiñe de un valor afectivo, dibujando toda una jerarquía sentimental y práctica. Si el latín goza del prestigio escolar y de su inactualidad de lengua muerta o el italiano de la feliz extraterritorialidad del habla de las vacaciones, el francés es la lengua impuesta por los aprendizajes escolares y de la experiencia incómoda de la extrañeza ("Al principio ni siquiera entendía cuando un profesor me llamaba por mi apellido, porque lo pronunciaban a la manera francesa, con una sola sílaba" (Borges, 1999 : 28)) mientras que el alemán es el idioma de un rito privado, de una iniciación elegida, un temprano ejercicio de libertad poética y filosófica ("Por mi cuenta, fuera del colegio empecé a estudiar alemán", "Conseguí un ejemplar de los primeros poemas de Heine, Lyrisches Intermezzo, y un diccionario alemán-inglés. Poco a poco, gracias al sencillo vocabulario de Heine, descubrí que podía leer sin el diccionario. Me había internado pronto en la belleza del idioma" (Borges, 1999 : 30)).

11 Así la neutralidad de la familia (fundada en el anarquismo heredado del padre y alimentada por el pacifismo del joven Borges) y de su lugar de estadía no impiden que se exprese en Borges una conciencia aguda de las fuerzas en presencia. Es más, la neutralidad exacerba esa conciencia y, más que un refugio a resguardo de la guerra, Suiza se vuelve una atalaya. Desde su colegio, a través de su manejo de las lenguas, de sus elecciones y silencios, el joven Borges dibuja su propia geografía, lingüística y literaria, de la guerra de posiciones europea. Este mapa íntimo de valores es el que recorre todavía el Borges autobiógrafo :

Todavía pienso que el alemán es un idioma muy hermoso ; quizá más hermoso que la literatura que ha producido. Paradójicamente, el francés tiene una buena literatura a pesar de su afición a las escuelas y los movimientos, pero el idioma en sí es, me parece, bastante feo. Las cosas resultan triviales cuando se las dice en francés. En realidad, considero que de los dos idiomas el español es el mejor, a pesar de que sus palabras sean demasiado largas y pesadas. Como escritor argentino tengo que sobrellevar el español, y soy demasiado consciente de sus deficiencias. Recuerdo que Goethe escribió que tenía que tratar con el peor idioma del mundo : el alemán. Supongo que la mayoría de los escritores piensan de la misma manera acerca del idioma con el que tienen que luchar (Borges, 1999 : 32).

12 Conviene detenerse y no dejarse llevar por una lectura apresurada de las declaraciones borgeanas. La crítica se ha encargado de relativizar la presunta francofobia del escritor alimentada por declaraciones similares y ya no cabe duda de que tanto la lengua como la biblioteca francesas desempeñaron un papel fundamental en la formación del escritor y ocupan un lugar en su espacio mental y afectivo9. El debate se sitúa en otra parte. La guerra de Borges no es un enfrentamiento de nacionalismos -o la preferencia teñida de dandismo por la lengua del enemigo- sino la metáfora de una compleja pero vivificadora convivencia de lenguas.

13 La comparación con las posiciones de los nacionalistas argentinos respecto a la Gran Guerra permite precisar la compleja postura de Borges. Para los medios nacionalistas argentinos, la Primera Guerra Mundial puso al desnudo la decadencia europea, tema que será luego un tópico del discurso de entreguerras. Si en Buenos Aires, se compartía la sensibilidad europea de posguerra marcada por un sentimiento de rebeldía contra los 
valores tradicionales, se consideraba sin embargo que la Argentina era el nuevo receptáculo de la vitalidad y el espíritu que habían abandonado la agotada Europa (Compagnon, 2013 : 193). Gracias a este milagroso traslado, el nacionalismo argentino se presentaba como el beneficiario simbólico de la Primera Guerra Mundial ${ }^{10}$. Si bien Borges frecuentó el círculo nacionalista a su vuelta de Europa, a través de la revista Inicial (Louis, 2006 : 138), era inmune a la "ceguera política nacionalista" (Panesi, 2007 : 168). Según Jorge Panesi, los "antídotos" eran dos : "una concepción del sujeto que se aviene mal con el enfático ego de las nacionalidades" y "una reflexión crítica sobre el lenguaje" (168).

Nuestra hipótesis es que la experiencia plurilingüística de Borges durante la guerra es una de las fuentes de su inconformidad con los presupuestos lingüísticos (una lengua unificada, expresión "natural" de la nación) y ontológicos (un sujeto fuerte y unificado, base y analogía de la nación) del nacionalismo, inconformidad expresada en los fervorosos ensayos de los años 20 (Inquisiciones, El tamaño de mi esperanza, El idioma de los argentinos). Si no existe un "yo de conjunto", el yo horadado por una ilusión o una nadería es entonces un ser fundamentalmente abierto, un "hueco" donde "se aloja el otro, los otros" (Panesi, 2007 : 168), un "yo interiormente habitado por otras voces" (Panesi, 2007 : 168), y, añadimos, otras lenguas. Si cada idioma forja su representación del mundo, vivir, pensar e imaginar en distintos idiomas es una experiencia de apertura, un vaivén no sólo entre idiomas sino entre "mundos de pensamiento ${ }^{11}$ ". Y esta experiencia corresponde a la forma de pensar borgeana para quien "el encuentro con lo otro equivale en su concepción al pensamiento" (Panesi, 2007 : 168) : "Yo no niego esa conciencia de ser, ni esa seguridad inmediata del aquí estoy yo [...] Lo que sí niego es que las demás convicciones deban ajustarse a la consabida antítesis entre el yo y el no yo y que esta sea constante" (Borges, 1993 : 96).

Pero este encuentro con el otro no es en absoluto pacífico. En efecto, lo que llama la atención en el relato de Borges es la modalidad de esta apertura lingüística engendrada por la guerra: nada de encuentro armonioso y ecuménico con un otro sublimado. El encuentro es en realidad un choque. Los humores del joven aprendiz subrayan la experiencia de la materialidad de la lengua, cuya textura se resiste (las sonoridades incómodas del francés, lenguaje "feo") o, al contrario, se ofrece al disfrute (la facilidad del aprendizaje del alemán). En este enfrentamiento el yo debe negociar su lugar, bajo la forma de un constante ajuste entre el aquí y el allá, en un entre-dos a menudo incómodo. Sólo después la contienda se traslada a un nivel imaginario, donde se dibuja una guerra de trincheras lingüísticas en la cual el idioma ostenta su "función belicosa" (Steiner, 1998 : 69).

De manera que la guerra, en el relato autobiográfico de Borges, es finalmente un acontecimiento lingüístico cuya fuerza reside en dos poderosos efectos : la guerra enfatiza la conciencia de que se escribe desde un lugar y que para escribir se elige una lengua; transmite un sentido combativo de la literatura. Estos efectos encuentran enseguida su realización práctica : el relato de los años de guerra desemboca en la elección del español como lengua de escritura mientras que la concepción belicosa de la literatura se expresará sin tardar en la batalla de las revistas donde Borges se distinguirá por su talento polémico, primero en España y luego a su vuelta a Buenos Aires. Del primero de estos efectos, Borges da cuenta con un sentido consumado de la fatalidad trágica :

Yo había estado escribiendo sonetos en inglés y en francés. Los sonetos en inglés eran malas imitaciones de Wordsworth, y los sonetos en francés copiaban, de manera acuosa, la poesía simbolista. Todavía recuerdo una línea de mis experimentos franceses : "Petite boîte noire pour le violon cassé". El texto completo 
se titulaba "Poème pour être récité avec un accent russe". Sabiendo que escribía un francés de extranjero, pensé que era mejor un acento ruso que uno argentino. En mis experimentos con el inglés adoptaba algunas peculiaridades del siglo dieciocho, como "o'er" en vez de "over" y, para mayor facilidad métrica, "doth sing" en vez de "sings". Pero no ignoraba que el español era mi destino ineludible (Borges, 1999 :

40).

De nuevo conviene detenerse en las ambiguas declaraciones del autor ya que precisan el complejo legado lingüístico de la guerra. La aparente sumisión de Borges a su destino es en realidad un juego y una paradoja. Un juego porque a través de la fatalidad lingüística el español como "destino ineludible"- se da a leer un tópico, el del amor-odio del escritor por su lengua materna, pathos que Borges manipula con perfecta conciencia y que ya mencionó al referirse a los disgustos de Goethe con el alemán ${ }^{12}$. Una paradoja porque un primer acercamiento indicaría que el español, al imponerse sobre las otras lenguas, anula las infructuosas experiencias anteriores en inglés y en francés, reducidas a ser simples devaneos juveniles. Pero la palabra "destino" señala que Borges aplica al español la concepción histórica que hereda de Schopenhauer "para quien la Historia se compone de individualidades y contingencias imprevisibles, no totalizables o reguladas por una finalidad universal, tal como Borges dice del destino : 'la infinita operación incesante de millares de causas entreveradas"' (Panesi, 2007 : 172). El inglés, el francés o el alemán no son excursiones accidentales en el camino hacia el español. Quizás, en esta verdadera pugna de lenguas a través de la cual buscó forjarse su propio idioma, el español le haya vencido, imponiéndose con la eficacia estética que no podían proporcionarle su manejo del inglés, del francés o del alemán. Sin embargo, todos son componentes, antagónicos y belicosos, de la lengua de Borges, heredados de la práctica temprana de la traducción y de la escritura en otros idiomas.

\section{Zona de traducción}

De la época de la guerra datan poemas inspirados por la contienda, pero también traducciones y reseñas que muestran las distintas maneras en que la guerra se hace presente en la producción del joven Borges: como un tema y a través de un multilingüismo belicoso.

Así, contrastando con la despreocupación ostentada en la autobiografía, la guerra fue material de inspiración poética para el joven escritor, que no era ni mucho menos inmune a la tonalidad del momento. Entre sus primeros poemas ultraístas, hay uno que se refiere a la guerra de trincheras y recuerda la vasta literatura de guerra de la época de la cual Borges era un asiduo lector como lo atestiguan su severa reseña de un libro de Romain Rolland para la revista Ultra en $1921^{13}$, o su "biografía sintética de Henri Barbusse" donde al comentar Le Feu, el libro-símbolo de una generación de poilus horrorizados por la boucherie de la Gran Guerra, dice que "de las trincheras sacó el glorioso libro de barro y sangre $^{14 "}$. En "Trinchera" (1920), Borges escribe :

Angustia

En lo altísimo una montaña camina

Hombres color de tierra naufragan en la grieta más baja

El fatalismo unce las almas de aquéllos

que bañaron su pequeña esperanza en las piletas de la noche

Las bayonetas sueñan con los entreveros nupciales

El mundo se ha perdido y los ojos de los muertos 
Lo buscan

El silencio aúlla en los horizontes hundidos ${ }^{15}$.

Si bien Borges no recorrió el lugar emblemático de la guerra del 14, en su propia "trinchera" estalla, desde el primer verso, el grito de desesperación de una época y de una generación. La experiencia de la guerra (la topografía desolada, el agotamiento de los combatientes presos del barro) pero sobre todo su proyección moral (el trastorno de dimensiones cósmicas y el silencio que reúne vivos y muertos en un mismo ejército de fantasmas) aparecen claramente en un poema que pertenece de lleno al inmenso archivo de los textos literarios engendrados por la contienda, donde se expresa un pacifismo marcado por el horror de la guerra, la desesperación ante la catástrofe humana y la meditación sobre el destino de la historia y de la cultura occidentales.

"Trinchera" es un testimonio indirecto de la guerra, porque es mediado por las lecturas de los poemas antibélicos de los expresionistas alemanes que Borges traduce para la revista Cervantes y reseña para la revista Ultra en $1920^{16}$. La traducción es aquí, clásicamente, imitatio, escuela de escritura y de pensamiento. Para Borges, traducir es, en un mismo gesto, emular a los expresionistas alemanes y heredar su pacifismo. La traducción es a la vez un aprendizaje estético y el gesto político accesible para el adolescente recluido en Suiza, su manera de protestar contra la guerra ${ }^{17}$.

La traducción es también un puente para compartir experiencias, y en estos años todas giran alrededor de la guerra. Borges traduce al francés "Angustia" un poema de Jacobo Sureda, su amigo mallorquín, para su compañero del colegio suizo, Maurice Abramowicz ${ }^{18}$ . Llama la atención la comunidad de pensamiento y de palabras para expresar un mismo sentir ("Angustia", título del poema de Sureda es también la palabra que abre el poema "Trinchera" de Borges). Además, en "Poème", traducción del poema de Sureda, el profundo desamparo engendrado por la barbarie se expresa en la imagen de una infancia rota, particularmente apreciada por Borges que dice a su amigo ginebrino "encontrar muy buenos los versos quinto y sexto":

L'encensoir du néant

consommait un vaste holocauste

sans idole et sans rite

Ils me laissèrent si seul

toutes les heures dans les mains

comme des jouets cassés.

Sans rencontrer un nid

mes cris revinrent transis et moi

J'ai suivi le silence (Borges, 1997 : 55).

Para estos escritores aún muy jóvenes, el traumatismo colectivo de la guerra se expresa con los objetos ("jouets cassés") y las emociones de la infancia. Es también una prueba más de la necesidad de relativizar la indiferencia, sin duda táctica, de Borges frente a los acontecimientos históricos.

La guerra no fue sólo un tema de inspiración poética para Borges y sus amigos o el cimiento de una amistad vivida en traducción. La atmósfera bélica se trasladó, como lo vimos, al aprendizaje de los idiomas y no tardó en manifestarse también en los primeros pasos de Borges en la crítica, con "Chronique des lettres espagnoles. Trois nouveaux livres », reseña de tres libros publicada el 20 de agosto de 1919 en el diario La feuille de Ginebra $^{19}$. En su primer artículo crítico, Borges no sólo emplea la lengua de Molière sino que adopta la característica actitud gala ante su vecino ibérico, hecha de asombro y curiosidad por lo exótico ( Dans cette morne Espagne, dans ce pays de gaieté factice où 
les jours se traînent las et accablés sous la splendeur du soleil radieux et monotone, les écrivains sincères se sont toujours montrés sceptiques ou tristes ») y de desprecio por el provincianismo y el obscurantismo de las letras españolas (a propósito del tercer libro reseñado, de Ramón Ruiz Amado, jesuita y "auteur d'une histoire universelle ad usum scholarum", Borges escribe : "Dans ce livre, il s'agit de ramener à l'Eglise les libertins et les âmes perverties par les arguments de Voltaire. Il est bien curieux de constater que dans un pays où seuls quelques érudits connaissent le Dictionnaire Philosophique, ce pauvre Arouet continue à être l'épouvantail, la bête noire des pieuses gens").

Borges escribe su reseña a partir de cierto imaginario del francés. Si el alemán fue para él la lengua de la poesía, el francés es, clásicamente, la lengua del análisis y de la crítica elegante e ilustrada. Si bien fue declarado "feo" por el joven aprendiz, el francés tiene la virtud de la claridad y la distinguida crueldad del mot d'esprit. Así, con espíritu voltairiano, en su artículo, Borges hace gala de un talento polémico cuya ausencia lamenta, con un evidente sentimiento de superioridad, en los libros españoles reseñados. En efecto, comentando un libro de Azorín sobre la actitud de España durante la Primera Guerra mundial, observa con ironía : "C'est bien le livre le plus calme qu'ait inspiré la guerre » (Borges, 1997 : 24).

Más que un simple retruécano de colegial empapado de espíritu francés, el oxímoron muestra dos cosas : un estilo y una conciencia. Borges pone en práctica, con evidente deleite, ante su amigo (Maurice Abramowicz) y primer lector, las reglas del juego literario. Con su escaramuza Borges muestra que domina un estilo en el cual ambos se inician juntos, como lo atestigua su rica correspondencia. En efecto, las cartas escritas en francés que Borges manda a Abramowicz desde Mallorca y Madrid en los años 1919-1921 rezuman la pasión de « l'orgie polémique »:

Dans le Festival Ultraïste à Madrid, un grand scandale. Les cris et les hurlements d'indignation du public ont totalement noyé l'audition de 2 miens poèmes. Les œuvres des autres frères de l'ultra ont subi le même sort.

Demain je monte à Valldemosa, voir Sureda et concerter avec lui les moyens pour avoir une polémique avec l'anonyme, ce qui serait excellent comme propagande et très amusant, en outre.

[...] nous avons fabriqué, Jacobo et moi, deux répliques, l'une ironique, logique, mesurée, signée Sureda et qui a paru avant-hier à Palma; l'autre violente, âcre, proclamatoire, signée J.L.B. que j'ai expédiée hier et qui -hélas- ne se publiera peutêtre point, vu que notre ennemi est persona grata chez tous les rédacteurs des Journaux ${ }^{20}$.

27 Las intrigas de la vida literaria exigen de quien quiere lanzarse en ellas las virtudes morales del soldado : camaradería (les "autres frères") determinación ("Demain je monte à Valldemosa") y preparación ("concerter avec lui les moyens pour avoir une polémique"). Una considerable diferencia distingue sin embargo el arte de la guerra literaria de su émulo militar : su ligereza ("ce qui serait [...] très amusant") de bricolaje ("Nous avons fabriqué, Jacobo et moi, deux répliques") nos recuerda que son dos jóvenes apenas salidos de una tardía infancia quienes se transmiten una energía mutua antes de salir al combate. Pero el júbilo infantil esconde una reflexión. En efecto el sarcasmo ante el libro de Azorín traduce también la conciencia que el escritor debe estar a la altura de las circunstancias. Escribir un libro tibio sobre la guerra es un error de apreciación no sólo literaria (las reglas clásicas, que el colegial Borges aprendió hace poco, enseñan que el estilo debe corresponder a la materia) sino intelectual. 

Abramowicz y Jacobo Sureda, los amigos de la tardía infancia, sugiere que Borges vive la guerra en función de la lengua que adopta o traduce : expresa tanto la "angustia" de la poesía expresionista alemana como el ethos polémico del bel esprit francés. A cada lengua su visión del acontecimiento histórico o su particular sentir. La experiencia de la guerra en Borges pasó por el filtro de los textos y de las lenguas y nos da un singular ejemplo de que el idioma, más que un simple medio de expresión, es el vehículo de un imaginario.

Pese a lo que nos dice el mito, Borges no estuvo en absoluto Au-dessus de la mêlée $e^{21}$. Su experiencia de la guerra fue ante todo lingüística y dejó un legado de gran trascendencia. La práctica apasionada y belicosa de las lenguas y de la literatura enseñan al joven Borges que no hay lengua de conjunto (una y unificada), del mismo modo que no hay un "yo de conjunto". Más aún, le enseñan que vivir la lengua en la que uno escribe como una paradoja de la historia personal supone dar cabida a la diversidad lingüística que lo constituye. Esas son las huellas que los años de guerra dejaron en Borges : las primicias de lo que Sylvia Molloy designa como "a translational sensibility ${ }^{22 "}$ o, dicho de otra forma, una reflexión sobre la lengua y la nación que se formalizará en el debate argentino de los años 20

\section{BIBLIOGRAFÍA}

Balderston, Daniel. ¿Fuera de contexto ? Referencialidad histórica y expresión de la realidad en Borges. Rosario : Viterbo editora, 1996.

Borges, Jorge Luis. "La nadería de la personalidad”, Inquisiciones (1925). Barcelona : Seix Barral, 1993.

Borges, Jorge Luis. Textos recobrados, 1919-1929, ed. al cuidado de Sara Luisa del Carril. Buenos Aires : Emecé, 1997.

Borges, Jorge Luis. Autobiografía, 1899-1970, trad. de Marcial Souto y Norman Thomas di Giovanni. Buenos Aires : El Ateneo, 1999.

Borges, Jorge Luis. Cartas del fervor : correspondencia con Maurice Abramowicz y Jacobo Sureda (1919-1928), prólogo de Joaquín Marco, trad. de Marietta Gargatagli, notas de Carlos García, ed. al cuidado de Cristóbal Pera. Barcelona : Galaxia Gutenberg, 1999.

Cámpora, Magdalena. “Cenáculos, sectas, batallas incruentas. Sobre la Correspondencia en francés de Borges (1919-1921)”, Ana Gallego Cuiñas y Erika Martínez (eds.). Queridos todos. El intercambio espistolar entre escritores hispanoamericanos y españoles del siglo XX. Bruxelles, Bern, Berlin, Frankfurt am Main, New York, Oxford, Wien : Peter Lang, 2013, p. 193-206.

Compagnon, Olivier. L'adieu à l'Europe. L'Amérique latine et la Grande Guerre. Paris : Fayard, 2013.

Didier Alexandre et Madeleine Frédéric. Que se passe-t-il ? Événements, sciences humaines et littérature. Rennes : PUR, 2004.

Dosse, François. Renaissance de l'événement. Un défi pour l'historien : entre sphinx et phénix. Paris : PUF, 2010.

Cuadernos LIRICO, 11 | 2014 
Gilles, Philippe. Le rêve du style parfait. Paris, PUF : 2013.

Krystal, Efraín. Invisible work. Borges and Translation. Vanderbilt University Press, 2002.

Louis, Annick. Jorge Luis Borges : œuvre et manœuvres. Paris : L'Harmattan, 1997.

Louis, Annick. Borges face au fascisme, 1. Les causes du présent, Montreuil : Aux lieux d'être, 2006.

Molloy, Sylvia. "Lost in translation : Borges, the Western Tradition and Fictions of Latin America" en Evelyn Fishburn (ed.), Borges and Europe revisited. London : Institute of Latin American Studies, University of London, 1998, p. 8-20.

Panesi, Jorge. Críticas, Buenos Aires : Norma, 2000.

Panesi, Jorge. "Borges : destinos sudamericanos y destinos de la traducción” en William Rowe, Claudio Canaparo y Annick Louis. Jorge Luis Borges. Intervenciones sobre pensamiento y literatura. Buenos Aires : Paidós, 2007, p. 165-175.

Rodríguez Monegal, Emir. Borges, una biografía literaria. México : FCE, 1987.

Steiner, George. Après Babel, une poétique du dire et de la traduction. Paris : Albin Michel, 1998.

\section{NOTAS}

1. Jorge Luis Borges, Textos recobrados, 1919-1929, ed. al cuidado de Sara Luisa del Carril. Buenos Aires : Emecé, 1997.

2. Jorge Luis Borges, Cartas del fervor: correspondencia con Maurice Abramowicz y Jacobo Sureda (1919-1928), prólogo de Joaquín Marco, trad. de Marietta Gargatagli, notas de Carlos García, ed. al cuidado de Cristóbal Pera. Barcelona : Galaxia Gutenberg, 1999.

3. Una serie de trabajos recientes reevalúan el lugar de la guerra del 14 en la historia latinoamericana mostrando que fue un acontecimiento de gran trascendencia en el continente, en particular en la Argentina. Por su participación en la contienda, su vínculo histórico con el viejo continente, la Argentina y Brasil en particular conocieron una fuerte movilización psicológica, política y hasta cierta medida material que desembocó en la emergencia de una verdadera "cultura de guerra". Pero mas allá de la solidaridad con el viejo continente, la guerra desarrolló en América latina una fuerte desilusión frente a Europa: la civilización había engendrado la barbarie. Este sentimiento de un cambio de fuerzas perturbó la conciencia latinoamericana, forzándola a pensar de nuevo sus valores y referencias. Uno de los efectos de esta conmoción psicológica y cultural fue el fortalecimiento del nacionalismo argentino (y brasileño), una consecuencia que cambió el rumbo político de los dos países, cf Olivier Compagnon, L'adieu à l'Europe. L'Amérique latine et la Grande Guerre, Paris, Fayard, 2013.

4. Pascale Casanova, La république mondiale des lettres, Paris, Seuil, 1999.

5. La distancia que asume Borges ante la guerra en su autobiografía es particularmente llamativa si se piensa que los virulentos debates europeos, y en particular franceses, de los años 20 y 30 sobre el compromiso del intelectual en la guerra (a raíz de la publicación de La trahison des clercs de Julien Benda en 1927) entran en un fructífero diálogo con el clásico debate de las armas y las letras expuesto en el Quijote de Menard, $c f$ Daniel Balderston, ¿Fuera de contexto ? Referencialidad histórica y expresión de la realidad en Borges. Rosario : Viterbo editora, 1996, p. 35-68. El desfase entre el testimonio personal marcado por la indiferencia por los hechos históricos y el conocimiento del mismo contexto histórico e intelectual de la guerra en "Pierre Ménard, autor del Quijote" puede leerse como una manifestación de la tensión que, según Beatriz Sarlo, define el lugar que ocupa la obra de Borges, entre la mezcla y la nostalgia por una literatura (y una 
historia) europea que "un latinoamericano nunca vive del todo como naturaleza original", $c f$. Beatriz Sarlo. Borges, un escritor en las orillas. Buenos Aires : Ariel, 1995.

6. Para una crítica de esta lectura descontextualizada de la obra de Borges, ver Daniel Balderston, ¿Fuera de contexto ?, op.cit. (en particular el capitulo 3, de especial interés para nuestro tema, ya que propone una lectura del cuento "El jardín de los senderos que se bifurcan" en relación con la Batalla de la Somme de 1916) . Para la influencia de la recepción francesa sobre la lectura descontextualizada y por "temas" de la obra de Borges, ver Sylvia Molloy. La Diffusion de la littérature hispano-américaine en France au XXe siècle. Paris : PUF, 1972 y Annick Louis. Borges face au fascisme, 1. Les causes du présent, Montreuil: Aux lieux d'être, p. 320-323. Prueba de su continuidad, esa lectura clásica en la recepción francesa aparece en la introducción de François Dosse. Renaissance de l'événement, op.cit., p. 9.

7. Corresponsal en París para La Nación entre 1912 y 1914, Lugones reunió sus reflexiones sobre la Gran Guerra en Mi beligerencia. Desde el ideario nacionalista de marcados acentos nietzcheanos, Lugones reivindica la plena participación de la Argentina en la guerra, al lado de Francia defensora, según él, del «ideal latino », contra « el dogma asiático de la obediencia, que tomó a los bárbaros del Norte como instrumento político para subyugar, destruyéndolo, al mundo romano ", cf Mi beligerancia, Buenos Aires : Otero y García, 1917, p. 11.

8. Si en su autobiografía, Borges se presta al juego de construcción de su figura de autor confirmando los caracteres de su obra (irrealidad y autoreferencialidad) definidos por su recepción internacional, expresó en otros textos su interés histórico por la Primera guerra mundial, en particular a través de su conocimiento de la obra clásica del historiador Liddell Hart (La historia de la guerra mundial, 1934) una de las claves de lectura de "El jardín de los senderos que

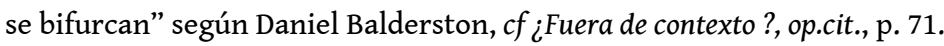

9. Ver Emir Rodríguez Monegal. «La biblioteca circulante francesa " en Borges, una biografía literaria, op.cit., p. 103-113 y Magdalena Cámpora y Javier Roberto González (dir.). Borges-Francia. Buenos Aires : Publicación de la Facultad de Filosofía y Letras, 2011.

10. La mejor expresión de esta filosofía de la historia según la cual América toma el relevo de Europa se encuentra en Lugones : "La civilización, de la cual formamos parte, habría consistido en una perpetua lucha de libertad pagana con el dogma asiático de la obediencia, que tomó a los bárbaro del Norte como instrumento político para subyugar, destruyéndolo, al mundo romano ; y esto es lo que iría determinando la catástrofe actual cuyo desenlace creo favorable al ideal latino, porque su preparación ha consistido - al menos desde la Revolución Francesa- en sucesivos recobros de ese mismo ideal. Ellos comportan ya un triunfo moral en el mundo entero; de suerte que su magnitud excede infinitamente la de aquellas re- surecciones análogas que tuvieron por teatro a la Francia revolucionaria y a la Provenza de los albigenses. La insurrección emancipadora de las Américas, fué uno de esos episodios, y hé aquí la primera razón histórica de nuestro papel en la contien- da actual", $c f$ Leopoldo Lugones, Mi beligerancia, op.cit., p. 11.

11. Nos referimos aquí a la clásica (y por ende discutida) tesis de la lingüística relativista, heredera de los trabajos de Humboldt y contemporánea de la antropología, inspirada en la física relativista y la Gestalt y divulgada por los trabajos de Benjamin Lee Whorf sobre la lengua de los Hopis a finales de los años 30, cf Language, Thought and Reality: Selected Writings of Benjamin Lee Whorf, ed. John B. Carroll, Cambridge, 1956. Ver también George Steiner. Après Babel, une poétique du dire et de la traduction (1975). Paris : Albin Michel, 1998, p. 137-145.

12. La descalificación del español, fatal destino del escritor, es, según Jorge Panesi, fruto de la experiencia de otra lengua, el alemán, “ [Borges] siente su idioma español como un destino minusválido, como el tosco sedimento de una cultura cuyo élan literario se cierra, sin reabrirse, en las magnificiencias verbales del Siglo de Oro; expansiones literarias de la lengua que son aceptadas para, inmediatamente, ejercitar sobre ellas, la crítica feroz. La sustancia de esta crítica proviene de otra lengua que Borges ha aprendido en Ginebra y que se ha empecinado en no olvidar : el alemán », cf. Jorge Panesi, Críticas, Buenos Aires, Norma, 2000, p. 132. 
13. Jorge Luis Borges, "Roman [sic] Rolland, Clérambault, París 1920", Textos recobrados, 1919-1929. Buenos Aires : Emecé, 1997, p. 49.

14. Jorge Luis Borges, Textos cautivos. Ensayos y reseñas en El Hogar, 1936-1939. Barcelona: Tusquets, 1986, p. 106.

15. En « Rusia », también publicado en la revista madrileña Grecia en 1920, se encuentra también una evocación de la guerra con el típico paisaje de la trinchera, $c f$. Jorge Luis Borges, Textos recobrados 1919-1929, op.cit., p. 49 y 56-57.

16. Cf Jorge Luis Borges, “Antología expresionista” y "Horizontes. Die Aktions-Lyric (1914-1916), Berlín”, Textos recobrados, op.cit., p. 61-70 y 105-107. La meditación borgeana sobre el expresionismo desemboca en el ensayo "Acerca del expresionismo", Inquisiciones (1925).

17. E. Krystal relaciona el pacifismo de Borges con su traducción de los expresionistas : "Borges's encounter with Whitman and with German Expressionism, while his family was safely trapped in Switzerland during the First World War, led to a literary vision best summarized by Emir Rodríguez Monegal: "He could not help feeling the impact of those poems that violently attacked war and proclaimed the need for all men to unite in a universal brotherhood." This vision informs both his essays on the Expressionist movement, and his translations. Many of the poems Borges translated were a protest against war." cf. E. Krystal, Invisible Work. Borges and Translation. Vanderbilt University Press, 2002, p. 43.

18. En su correspondencia, Borges se muestra muy consciente de este papel de puente, "hilo conductor" que desempeña entre sus amigos y sus respectivos textos, ver por ejemplo la carta a Sureda del 4 de octubre de 1920 : "Tu poema aquel de las líneas estupendas 'me dejaron tan solo / y con todas las horas...' ya debe estar en la custodia del Porta-estandarte [Vando Villar] a quien se lo mandé. Le mandé también una copia al otro prosélito que he traído yo al ultra, al lírico ironizante judío Maurice Claude. Este -desde Ginebra- te transmite sus felicitaciones, sirviendo yo de hilo conductor", cf. Cartas del fervor, op.cit., p. 164.

19. Ibid., p. 22-24. El texto fue corregido por Abramowicz y publicado por su mediación en La feuille, prueba más de que el manejo de las lenguas está íntimamente relacionado con los años de amistad de colegio. Sobre esta cuestión del francés como lengua de la «juvenilia », de la polémica literaria y de la programación poética, ver Magdalena Cámpora, "Cenáculos, sectas, batallas incruentas. Sobre la Correspondencia en francés de Borges (1919-1921)”, Ana Gallego Cuiñas y Erika Martínez (eds.). Queridos todos. El intercambio espistolar entre escritores hispanoamericanos y españoles del siglo XX. Bruxelles, Bern, Berlin, Frankfurt am Main, New York, Oxford, Wien : Peter Lang, 2013, p. 193-206.

20. Jorge Luis Borges. Cartas del fervor: correspondencia con Maurice Abramowicz y Jacobo Sureda (1919-1928), prólogo de Joaquín Marco, trad. de Marietta Gargatagli, notas de Carlos García, ed. al cuidado de Cristóbal Pera. Barcelona: Galaxia Gutenberg, 1999, p. 102, 110-111 y 114. Para un análisis de estas, ver Magdalena Cámpora, op.cit., p. 200-202.

21. Au-dessus de la mêlée es el título de un célebre artículo del escritor pacifista francés Romain Rolland publicado el 22 de septiembre de 1914 en el suplemento del Journal de Genève.

22. Sylvia Molloy toma el término del crítico cubano-americano Gustavo Pérez Firmat quien en The Cuban Condition define esta "condición" como fundamentalmente vinculada a la experiencia de la traducción, del desplazamiento y de la apropiación a partir del concepto de transculturación del antropólogo Fernando Ortiz. Molloy considera que Borges "representa perfectamente esta entonación" argentina y latinoamericana frente a la cultura europea. La crítica define esta sensibilidad como una "interpretación" o "relación", un proceso cultural sin resolución ni término, una traducción con sus fructíferos errores o aún, citando al propio Borges, un "criollismo conversador del mundo", cf. Sylvia Molloy. "Lost in translation: Borges, the Western Tradition and Fictions of Latin America" en Evelyn Fishburn (ed.). Borges and Europe revisited. London : Institute of Latin American Studies, University of London, 1998, p. 8-20. 


\section{RESÚMENES}

Este ensayo reflexiona sobre la coincidencia entre la Primera Guerra Mundial y la tardía infancia de Borges, es decir, entre dos inicios, el histórico y el literario, el colectivo y el individual. Muestra que si bien la Autobiografía, como parte del proceso de canonización del escritor, sugiere una relativa indiferencia del joven Borges frente a la contienda mundial, los poemas y textos críticos del período, las traducciones y la correspondencia con los amigos de la época europea nos enseñan, al contrario, que la guerra de Borges fue un acontecimiento central, pero de carácter lingüístico e imaginario, el privilegio de la experiencia infantil y juvenil de la Historia. Se concluye que el legado de los años de guerra fue decisivo en la reflexión posterior del escritor sobre la lengua y la nación.

Cet article propose une réflexion sur la coïncidence entre la Première Guerre mondiale et l'enfance de Borges, soit entre deux commencements, l'un historique et collectif, l'autre littéraire et individuel. Tandis qu'Essai d'autobiographie, en tant qu'élément du processus de canonisation de l'écrivain, suggère que Borges aurait été indifférent au conflit mondial, les poèmes et les textes critiques de la même période, ainsi que les traductions et la correspondance du futur écrivain avec ses amis européens montrent au contraire que la guerre fut pour Borges un événement majeur, de nature linguistique et imaginaire, traduisant une expérience enfantine de l'Histoire. On en conclut que l'héritage de ces années de guerre fut décisif dans la réflexion ultérieure de l'écrivain sur la langue et la nation.

This article analyses the coincidence of the First World War and Borges' childhood, considered as two kinds of beginnings, historical and literary. It shows that whereas An Autobiographical Essay suggests, as part of the process of canonization of the writer, that Borges would have felt unconcerned by the conflict, the poems, critics, translations and correspondence of the same period prove, on the contrary, that the Great War was an essential time for the writer, a linguistic and imaginary event which reflects the way children live and understand History. It concludes that wartime's legacy will be highly significant in Borges' reflection on language and nation in the 20 's.

\section{ÍNDICE}

Mots-clés: première guerre mondiale, enfance, evénement, langue, Borges

Keywords: first world war, childhood, event, language

Palabras claves: primera guerra mundial, infancia, acontecimiento, lengua

\section{AUTOR}

\section{GERSENDE CAMENEN}

Université François-Rabelais Tours, ICD 